\title{
Zircon peaks marching through time argue for continuous crustal growth
}

\author{
CHRISTOPHER J SPENCER ${ }^{1}$
}

${ }^{1}$ Department of Geological Sciences and Geological

Engineering, Queen's University, Kingston, ON, Canada

Analysis of a database of $\sim 600,000$ detrital zircon ages constrained by the depositional ages of the respective sedimentary units reveals a dynamic evolution of zircon age peaks through time. This analysis demonstrates that zircon age peaks from ancient sedimentary successions are often out of phase with the detrital zircon record obtained from modern sediments. The growth and diminishment of the zircon age peaks through time implies the presence of continental crust whose age is not proportionately represented in the modern record, and therefore that the current crustal archive is biased. Taken as a time-lapse view of continental growth, it appears there never was a time in Earth history without an associated zircon age peak. The analysis of detrital zircon age peaks presented herein also reveals an evolution that can be broadly divided into three temporal groupings that broadly correspond with phases of Earth's tectonic evolution, namely presupercontinent continental growth (pre-2.1 Ga), Earth's middle age (2.1-0.8 Ga), and post-onset of modern-day plate tectonics (post- $0.8 \mathrm{Ga}$ ). These three groupings each display increasing degrees of zircon age diversification with time, and are a likely result of a net increase of preserved continental crust through time. The presence of these three tectonic states in multiple geologic proxies (detrital zircon ages, changing styles of metamorphism, paleogeography/supercontinents) suggests that while the growth of the continental crust is continuous, the tectonic processes that shape the long-term preservation of the crust have evolved over geologic time. 